\title{
USINAS EÓLICAS OFFSHORE NO DIREITO AMBIENTAL MARINHO
}

\section{Lucas Noura de Moraes Rêgo Guimarães}

Doutor em Direito pela Universidade Livre de Berlim, como bolsista do CNPq (2017). Mestre em Direito e Políticas Públicas pelo Centro Universitário de Brasília - UniCEUB (2011), onde recebeu bolsa institucional. Graduado em Direito pelo UniCEUB (2007). Conselheiro do Instituto Brasileiro de Direito da Energia - IBDE. Membro da Sociedade Brasileira de Planejamento Energético - SBPE e do Cigré-Brasil. E-mail: lucasnoura@hotmail.com

\section{RESUMO}

Este artigo visa inaugurar discussão a respeito da regulamentação ambiental brasileira das usinas eólicas offshore. Embora diante de fonte renovável de energia com crescente destaque no cenário mundial, sob o ponto de vista ambiental ainda é incerta qual a dimensão dos impactos causados à vida marinha pela instalação e operação de eólicas offshore. Enquanto a CNDUM dedicou um capítulo exclusivamente à proteção e preservação do meio marinho, experiências internacionais mostram que certos instrumentos são fundamentais à exploração sustentável do recurso, tais como EIA/RIMA, zonas de exclusão e planejamento ambiental. A legislação brasileira possui dispositivos com aplicação imediata às eólicas offshore, bem como contempla o aproveitamento dos ventos marítimos em instrumentos de planejamento.

Palavras-chave: Usinas eólicas offshore; Direito Ambiental marinho brasileiro; Regulamentação; Experiências internacionais; Impacto ambiental. 


\section{OFFSHORE WIND FARMS IN THE \\ ENVIRONMENTAL LAW OF THE SEAS}

\section{ABSTRACT}

This article aims to inaugurate the discussion surrounding the Brazilian environmental regulation of the offshore wind farms. Although it is a renewable source of energy with a growing prominence in the international scenario, from the environmental point of view it is still uncertain which are the dimensions of the impacts on marine wildlife caused by the installation and operation of an offshore wind farm. While UNCLOS dedicated one whole chapter to the protection and preservation of the marine environment, international experiences show that certain instruments are paramount to sustainable resource exploitation, such as EIA, exclusion zones and environmental planning. The Brazilian legislation contains some legal mechanisms with immediate use to offshore wind farms, as well as envisages the exploitation of maritime wind in planning instruments.

Keywords: Offshore wind farms; Brazilian Environmental Law of the Seas; Regulation; International experiences; Environmental impacts. 


\section{INTRODUÇÃO}

As usinas eólicas offshore, ainda inexistentes no Brasil ${ }^{1}$, são realidade em alguns países, demandando uma regulamentação jurídica para sua implantação e uso para captação dos ventos marítimos para fins de geração de eletricidade. Embora os ventos sejam considerados uma fonte renovável e limpa de energia, bem como constituam alternativa mais sustentável quando comparados aos combustíveis fósseis, seu aproveitamento energético não está completamente livre de impactos ambientais.

Embora estejam claros os impactos ambientais causados por usinas eólicas onshore, muito em razão da ampla difusão da técnica, para os aerogeradores offshore subsistem ainda dúvidas quanto ao tipo e à magnitude dos impactos ambientais causados pela sua implantação e uso. A falta de consenso quanto ao tema motivou e segue motivando a adoção de medidas variadas para a mitigação dos impactos ambientais. Nesse sentido, merecem análise problematizada os instrumentos jurídicos presentes no Direito internacional e estrangeiro que visam à proteção e gestão do meio ambiente marinho.

O presente artigo divide-se em cinco partes: inicialmente, são elencadas as vantagens e desvantagens ambientais quanto à implantação de uma usina eólica no mar (tópico II); em seguida, é feito um cotejo analítico da legislação ambiental brasileira aplicável às usinas eólicas offshore (tópico III); o mesmo é feito para o Direito ambiental conforme a Convenção das Nações Unidas para o Direito do Mar - CNUDM (tópico IV); por fim, adentra-se no estudo dos instrumentos utilizados pelo Direito estrangeiro na conciliação entre proteção do meio ambiente marinho e exploração econômica dos ventos offshore (tópico V); conclusões são apresentadas ao final (tópico VI).

\section{ASPECTOS AMBIENTAIS RELACIONADOS ÀS USINAS EÓLICAS OFFSHORE}

As usinas eólicas offshore apresentam uma série de vantagens, quando comparadas às usinas eólicas onshore. Essa série de vantagens,

1 Para uma discussão acerca da regulamentação da exploração do potencial eólico offshore brasileiro, cf. GUIMARÃES, Lucas Noura de Moraes Rêgo. Geração de eletricidade a partir de usinas eólicas offshore: premissas a serem consideradas. In: BORGES, Thiago Carvalho et al. (Orgs.). Direito do Mar Vol. 1 -Reflexões, tendências e perspectivas. Belo Horizonte: D’Plácido, 2017, p. 295ss. 
aliada aos cada vez mais comuns entraves à instalação de parques eólicos onshore, dentre eles a emissão de ruídos, shadow flicker ${ }^{2}$, poluição visual, especulação imobiliária, políticas $N Y M B Y^{3}$ e questões socioambientais ${ }^{4}$, fez com que a indústria eólica offshore se viabilizasse econômica e socioambientalmente em alguns países.

A vantagem principal é a presença de ventos mais fortes e mais constantes, o que, a uma só vez, aumenta o fator de capacidade ${ }^{5}$ das usinas eólicas localizadas no mar e atenua a intermitência da geração de eletricidade a partir dos ventos. Outras vantagens são: ausência de limitações em termos de utilização do solo e dos diversos impactos visuais; ausência de impactos sonoros (ao menos para seres humanos), devido a distância da costa ausência de obstáculos geográficos, tais como montanhas, contribuindo para ventos constantes; baixa rugosidade da superfície do mar, fazendo com que as turbinas não necessitem de grandes alturas, quando comparadas às usinas onshore; em termos globais, a turbulência do vento é muito inferior no mar, devido à ausência de barreiras, evitando desgaste exorbitante das turbinas e aumentando, consequentemente, sua vida útil; por fim, maior facilidade de transporte dos elementos constituintes dos aerogeradores por mar do que por terra.

Por outro lado, trata-se de tecnologia ainda em fase de desenvolvimento, razão pela qual apresenta algumas desvantagens de ordem econômica, tecnológica e ambiental. No que tange ao meio ambiente, vale mencionar o desconhecimento quanto à escala do impactos ambientais causados pela instalação e operação dos aerogeradores, especialmente para além do Mar Territorial, merecendo destaque os ruídos e vibrações causados nas obras de fundação (pile-driving noise) e na operação do aerogerador, alteração da geomorfologia, impactos no fundo do mar pela colocação de cabos de transmissão de eletricidade, bem como efeitos nocivos advindos do campo eletromagnético formado dentro

2 Shadow flicker descreve a alternância entre momentos de sombra e de luz ocasionada pela rotação das pás eólicas. Para sua ocorrência é necessária a concomitância de três fatores: incidência de luz solar em baixa angulação (nascer e pôr-do-Sol), localização da turbina entre o Sol e a propriedade afetada e ventos suficientes para fazer as pás se moverem. Um Estudo de Impacto Ambiental consegue antecipar a ocorrência do shadow flicker, evitando que turbinas sejam instaladas em determinados locais, cf. $\mathrm{http}: / /$ www.iwea.com/index.cfm/page/environmentalimpacts\#q72. Acesso em 04.11.2016.

3 Acrônimo para Not In My Backyard ("não no meu quintal"), referindo-se ao movimento de resistência de cidadãos contrários à instalação de usinas eólicas próxima às suas casas.

4 Merecendo destaque a instalação de usinas eólicas na rota de aves migratórias ou em áreas costeiras protegidas ambientalmente.

5 Fator de capacidade é o índice que aponta a relação, em um período dado, entre a produção efetiva de eletricidade por uma usina e a capacidade total máxima de geração de eletricidade.

6 Em média, as usinas eólicas offshore europeias distam $42 \mathrm{~km}$ da costa. 
dos cabos subterrâneos, quando estes estão transportando eletricidade ${ }^{7}$. Pássaros, peixes, mamíferos aquáticos e corais podem ser afetados, em alguma medida ainda incerta, pela instalação e operação de aerogeradores offshore. É sabido, a partir da experiência com eólicas onshore, que as turbinas muitas vezes são instaladas nas rotas migratórias de pássaros ${ }^{8}, o$ que demanda o uso de instrumentos e alternativas mitigadoras, visando à manutenção da exploração do potencial eólico de forma não lesiva à fauna (e flora) local. Para as usinas eólicas offshore não apenas aves são afetadas pelo giro das pás eólicas, mas também corais e os peixes transzonais e migratórios, em especial mamíferos aquáticos, em razão do pile-driving noise ${ }^{9}$.

Mais especificamente, os impactos ambientais se relacionam também a: modificação sedimentar e contaminação causada por descargas oriundas de perfurações; eliminação de material dragado; efeitos comportamentais e fisiológicos em mamíferos marinhos, pássaros e peixes causados pelo ruído oriundo de estudos sísmicos e geofísicos e pela presença humana; introdução de espécies não-nativas; riscos de colisão contra as pás eólicas; barreiras à movimentação de pássaros, peixes e mamíferos aquáticos; mudanças na água do mar relacionadas à salinidade, turbidez e temperatura; risco de acidentes tais como derramamento de produtos químicos, dentre outros ${ }^{10}$.

Nesse mister torna-se fundamental a existência de regras que compatibilizem a exploração econômica do potencial eólico offshore com a preservação do meio marinho, em especial dos habitats mais sensíveis.

7 Cf. a respeito ZEUSCHNER, Ruven Fleming. Pipelines and Cables - The Offshore Transportation of Oil, Gas and Renewable Energy. In: International Energy Law Review, vol. 8, 2011, p. 314; 317; GILL, A.B.; BARLETT, M. (2010). Literature review on the potential effects of electromagnetic fields and subsea noise from marine renewable energy developments on Atlantic salmon, sea trout and European eel. Escócia: Scottish Natural Heritage, Commissioned Report $\mathrm{N}^{\circ} 401,2010$.

8 CAINE, Catherine. The dogger bank offshore wind farm proposal: a study of the legal mechanisms employed in the construction of an offshore wind farm. In: North East Law Review, vol. 2, 2014, p. 93; PETERSEN, Ib Krag et al. Final results of bird studies at the offshore wind farms at Nysted and Horns Rev, Denmark. Dinamarca: National Environmental Research Institute, 2006; ZAMPIERI, Natália; CABRAL, Mariana. Os vieses da biodiversidade apresentados pelo caso do parque é́lico de Bald Hills. In: Revista de Direito Internacional, vol. 13, n. 2, 2016, pp. 263-275.

9 THOMPSON, Paul M. et. al. Framework for assessing impacts of pile-driving noise from offshore wind farm construction on a harbour seal population. In: Environmental Impact Assessment Review, vol. 43, 2013, pp. 73-85; BAILEY, Helen; BROOKES, Kate L.; THOMPSON, Paul M. Assessing environmental impacts of offshore wind farms: lessons learned and recommendations for the future. In: Aquatic Biosystems, vol. 10, 2014; CAINE, Catherine. The dogger bank offshore wind farm proposal: a study of the legal mechanisms employed in the construction of an offshore wind farm. In: North East Law Review, vol. 2, 2014, p. 94.

10 Disponível em: https://www.gov.uk/government/uploads/system/uploads/attachment_data/file /504874/OESEA3_Non-technical_summary.pdf. Acesso em: 30.01.2017. 


\section{O DIREITO AMBIENTAL BRASILEIRO APLICÁVEL ÀS USINAS EÓLICAS OFFSHORE}

Se for comparada a capacidade instalada atual das usinas eólicas onshore $(10 \mathrm{GW})$ com o potencial eólico mapeado em terras brasileiras $\left(146 \mathrm{GW}^{11}\right)$, entende-se a razão pela qual as usinas eólicas offshore ainda não ganharam impulso no país, nem de ordem jurídico-regulatório, nem de ordem econômico-financeira. Geralmente, a aventura de construir usinas eólicas no mar está associada ao esgotamento do potencial eólico terrestre, juntamente com a imposição de restrições socioambientais, circunstâncias que contribuem para a atratividade econômica da opção offshore ${ }^{12}$. Menos urgente, mas também importante, é a aquisição de know-how tecnológico (tome-se por exemplo a construção das usinas nucleares Angra I, II e III).

Sob o ponto de vista ambiental, os empreendimentos eólicos podem ser analisados quanto ao seu impacto ambiental (III.1) e quanto ao processo de licenciamento (III.2). Além destes dois aspectos, as usinas eólicas offshore também devem ser consideradas em razão do lugar que ocupam no planejamento ambiental (III.3).

\subsection{Quanto ao impacto ambiental}

No Brasil, o potencial eólico onshore está longe de se esgotar, mesmo considerando-se apenas as áreas de melhor potencial. Além disso, e ao contrário do que vem ocorrendo com a instalação de usinas hidrelétricas na Amazônia, cujos rios são considerados a "última fronteira a ser explorada" e onde a preservação do meio ambiente apresenta-se como intransponível e inconciliável com o uso dos recursos hídricos para geração de eletricidade ${ }^{13}$, os impactos socioambientais causados pela instalação de usinas eólicas onshore ainda são consideravelmente baixos.

A matéria está regulamentada pela Resolução CONAMA n ${ }^{\circ} 462$,

11 AMARANTE, Odilon Camargo; BROWER, Michael; ZACK, John; SÁ, Antonio Leite de. Atlas do Potencial Eólico Brasileiro. Brasília: Ministério de Minas e Energia, 2001. Disponível em: http:// www.cresesb.cepel.br/index.php?link=/atlas_eolico_brasil/atlas.htm. Acesso em 03.11.2016.

12 Quanto à baixa densidade populacional como fator que retarda a implantação de aerogeradores offshore, cf. SNYDER, Brian; Mark J. Kaiser. A comparison of offshore wind power development in Europe and the US: Patterns and drivers of development. In: Applied Energy, vol. 86, 2009, p. 1852.

13 Veja-se, a exemplo, a usina hidrelétrica de São Luiz do Tapajós, cujo processo de licenciamento ambiental foi arquivado pelo Instituto Brasileiro do Meio Ambiente - IBAMA em agosto de 2016, o que na prática significa a inviabilidade ambiental do projeto, tal qual concebido e apresentado ao Órgão Ambiental. No âmbito do processo, não apenas o IBAMA, mas também o Ministério Público Federal e a Fundação Nacional do Índio - FUNAI opinaram pela não construção da usina. 
de 24 de julho de 2014, que estabelece procedimentos para o licenciamento ambiental de empreendimentos de geração de energia elétrica a partir de fonte eólica em superfície terrestre. A edição da Resolução levou em conta o fato de empreendimentos de energia eólica possuírem baixo potencial poluidor e papel imprescindível na construção de uma matriz energética nacional mais limpa, bem como a necessidade de consolidar uma economia de baixo consumo de carbono na geração de energia elétrica de acordo com o Art. 11, parágrafo único, da Lei $n^{\circ} 12.187$, de 29 de dezembro de $2009^{14}$, que instituiu a Política Nacional sobre Mudança do Clima - PNMC. Ademais, a regulamentação dos procedimentos de licenciamento ambiental para instalação de usinas eólicas leva em conta "o compromisso nacional voluntário assumido pelo Brasil de redução das emissões projetadas até 2020, por força do Art. 12 da Lei no 12.187/0915" e a necessidade de "expansão de oferta de fontes alternativas renováveis, notadamente centrais eólicas, a fim de cumprir metas estipuladas para o setor de energia no Art. $6^{\circ}, \S 1^{\circ}$, III do Decreto $n^{\circ} 7.390$, de 9 de dezembro de $2010 " 16$.

Seu Art. $3^{\circ}$ atribui ao órgão licenciador o enquadramento do empreendimento de geração de energia eólica quanto ao impacto ambiental ${ }^{17}$, devendo ser considerados o porte, a localização e o baixo potencial poluidor da atividade. Quando o empreendimento eólico for considerado de baixo impacto ambiental ${ }^{18}$, o licenciamento ambiental

14 O parágrafo único do art. 11 dispõe que "decreto do Poder Executivo estabelecerá, em consonância com a PNMC, os Planos setoriais de mitigação e de adaptação às mudanças climáticas visando à consolidação de uma economia de baixo consumo de carbono, na geração e distribuição de energia elétrica, (...) com vistas em atender metas gradativas de redução de emissões antrópicas quantificáveis e verificáveis, considerando as especificidades de cada setor, inclusive por meio do Mecanismo de Desenvolvimento Limpo - MDL e das Ações de Mitigação Nacionalmente Apropriadas - NAMAs". (grifos adicionados).

$15 \mathrm{O}$ art. 12 fixa a meta (voluntária) de redução das emissões dos gases de efeito estufa entre $36,1 \%$ e $38,9 \%$ até 2020 .

16 Tratam-se dos considerandos da Resolução CONAMA nº 462/14. Disponível em: http://www.mma. gov.br/port/conama/legiabre.cfm?codlegi=703. Acesso 05.11.2016.

17 Impacto ambiental é, conforme definição do art. $1^{\circ}$ da Resolução CONAMA no 1 , de 23 de janeiro de 1986, qualquer alteração das propriedades físicas, químicas e biológicas do meio ambiente, causada por qualquer forma de matéria ou energia resultante das atividades humanas que, direta ou indiretamente, afetam a saúde, a segurança e o bem-estar da população (inciso I); as atividades sociais e econômicas (inciso II); a biota (inciso III); as condições estéticas e sanitárias do meio ambiente (inciso IV); a qualidade dos recursos ambientais (inciso V).

18 A legislação ambiental brasileira não define o que é um empreendimento eólico de baixo impacto ambiental. O Art. $4^{\circ}$ da Resolução CONAMA n ${ }^{\circ} 279$, de 27 de junho de 2001, estabelece que "o órgão ambiental competente definirá, com base no Relatório Ambiental Simplificado, o enquadramento do empreendimento elétrico no procedimento de licenciamento ambiental simplificado, mediante decisão fundamentada em parecer técnico". O Art. $2^{\circ}$, inciso I, da mesma Resolução, define Relatório Ambiental Simplificado como "os estudos relativos aos aspectos ambientais relacionados à localização, 
será realizado mediante procedimento simplificado, dispensando-se a apresentação de EIA/RIMA (Art. $\left.3^{\circ}, \S 2^{\circ}\right)^{19}$.

O seguinte $\S 3^{\circ}$ do Art. $3^{\circ}$ firma o rol das localizações onde a instalação de empreendimento eólico sujeita-se à apresentação de EIA/ RIMA e à realização de audiências públicas, hipótese na qual perde-se a condição de "empreendimento eólico de baixo impacto ambiental": em formações dunares, planícies fluviais e de deflação, mangues e demais áreas úmidas (inciso I); no bioma Mata Atlântica e implicar corte e supressão de vegetação primária e secundária no estágio avançado de regeneração, conforme dispõe a Lei $\mathrm{n}^{\circ} 11.428$, de 22 de dezembro de 2006 (inciso II); na Zona Costeira e implicar alterações significativas das suas características naturais, conforme dispõe a Lei $\mathrm{n}^{\circ} 7.661$, de 16 de maio de 1988 (inciso III); em zonas de amortecimento de unidades de conservação de proteção integral, adotando-se o limite de $3 \mathrm{~km}$ a partir do limite da unidade de conservação, cuja zona de amortecimento não esteja ainda estabelecida (inciso IV); em áreas regulares de rota, pousio, descanso, alimentação e reprodução de aves migratórias constantes de Relatório Anual de Rotas e Áreas de Concentração de Aves Migratórias no Brasil a ser emitido pelo ICMBio, em até 90 dias (inciso V); em locais em que venham a gerar impactos socioculturais diretos que impliquem inviabilização de comunidades ou sua completa remoção (inciso VI); e em áreas de ocorrência de espécies ameaçadas de extinção e áreas de endemismo restrito, conforme listas oficiais (inciso VII).

Uma interpretação sistemática do Art. $3^{\circ}$, levando-se em conta a ordem em que os dispositivos aparecem - primeiro o parágrafo sobre empreendimentos eólicos de baixo impacto ambiental e apenas depois o parágrafo sobre as localizações onde empreendimentos eólicos perdem a condição de baixo impacto ambiental -, permite a conclusão, portanto, de que, via de regra, os empreendimentos élicos onshore possuem baixo impacto ambiental, quando comparados aos demais empreendimentos instalação, operação e ampliação de uma atividade ou empreendimento, apresentados como subsídio para a concessão da licença prévia requerida, que conterá, dentre outras, as informações relativas ao diagnóstico ambiental da região de inserção do empreendimento, sua caracterização, a identificação dos impactos ambientais e das medidas de controle, de mitigação e de compensação". Vale destacar que a Resolução CONAMA n ${ }^{\circ}$ 279/2001 foi aprovada em momento no qual o País atravessava crise energética grave, necessitando de procedimento ambiental célere e simplificado para a implantação de empreendimentos energéticos. A Resolução CONAMA n ${ }^{\circ}$ 462/2014 não revoga a Resolução CONAMA n ${ }^{\circ} 279 / 2001$, sendo apenas específica para o licenciamento ambiental dos empreendimentos eólicos onshore.

19 O permissivo legal para o estabelecimento de procedimento simplificado para atividades e empreendimentos de pequeno potencial de impacto ambiental encontra-se no $\S 1^{\circ}$ do Art. 12 da Resolução CONAMA nº 237, de 19 de dezembro de 1997. 
para geração de eletricidade (em especial hidrelétricas e termelétricas), contribuindo para a viabilidade econômica do empreendimento, em razão de menores custos ambientais.

Saber se usinas eólicas offshore serão consideradas, pela legislação brasileira, de baixo impacto ambiental, a exemplo dos aerogeradores onshore, é incerto. Por se tratar de tecnologia nova, instalada em ambiente distinto do ambiente terrestre, onde os impactos ambientais ainda não foram completamente mensurados e conhecidos, recomenda a prudência e cautela que, ao menos inicialmente, as usinas eólicas offshore não sejam caracterizadas como de baixo impacto ambiental. Vale destacar que algumas das hipóteses de afastamento da caracterização do empreendimento como de "baixo impacto ambiental" tal como consta do $\S 3^{\circ}$ do Art. $3^{\circ}$ da Resolução CONAMA n ${ }^{\circ}$ 662/2014 já poderiam, por analogia, ser aplicadas às usinas eólicas offshore (incisos III, V e VII em especial).

\subsection{Quanto ao licenciamento ambiental}

No que diz respeito ao licenciamento ambiental, cabe anotar que, pelo Art. $4^{\circ}$ da Resolução CONAMA no 237, de 19 de dezembro de 1997, compete ao IBAMA o licenciamento ambiental, a que se refere o Art. 10 da Lei $\mathrm{n}^{\mathrm{o}}$ 6.938, de 31 de agosto de 1981, de empreendimentos com significativo impacto ambiental localizados no mar territorial, na plataforma continental e na Zona Econômica Exclusiva - ZEE, entre outros (inciso I).

Tal entendimento se coaduna com o disposto no Art. $7^{\circ}$, inciso $X I V$, alínea "b", da Lei Complementar $n^{\circ} 140$, de 8 de dezembro de 201120, o qual dispõe ser ação administrativa da União - nesse caso por meio de seu órgão ambiental, o IBAMA - promover o licenciamento ambiental de empreendimentos e atividades localizados ou desenvolvidos no mar territorial, na plataforma continental ou na ZEE.

Ainda, o Decreto $\mathrm{n}^{\circ} 8.437 / 15$ dispõe em seu Art. $3^{\circ}$, inciso VII, alínea "c", que "usinas eólicas, no caso de empreendimentos e atividades offshore e zona de transição terra-mar" serão licenciadas pelo órgão ambiental federal. Diferentemente do que ocorre para usinas eólicas onshore, cujos licenciamentos ambientais são executados pelos

20 Fixa normas, nos termos dos incisos III, VI e VII do caput e do parágrafo único do Art. 23 da Constituição Federal, para a cooperação entre a União, os Estados, o Distrito Federal e os Municípios nas ações administrativas decorrentes do exercício da competência comum relativas à proteção das paisagens naturais notáveis, à proteção do meio ambiente, ao combate à poluição em qualquer de suas formas e à preservação das florestas, da fauna e da flora; e altera a Lei n 6.938 , de 31 de agosto de 1981 . 
órgãos ambientais estaduais, para usinas eólicas offshore é competente o IBAMA, independente da distância do empreendimento em relação à costa brasileira.

\subsection{Eólicas offshore e o planejamento ambiental brasileiro}

No âmbito do planejamento ambiental, as usinas eólicas offshore recebem alguma menção. Vale destacar, inicialmente, a Lei n ${ }^{\circ}$ 7.661, de 16 de maio de 1988, que institui o Plano Nacional de Gerenciamento Costeiro - PNGC, com o objetivo de "orientar a utilização nacional dos recursos na Zona Costeira, de forma a contribuir para elevar a qualidade da vida de sua população, e a proteção do seu patrimônio natural, histórico, étnico e cultural" (Art. $2^{\circ}$ da Lei ${ }^{\circ} 7.661 / 88$ ).

O Art. $2^{\circ}$, parágrafo único, define Zona Costeira - ZC como o “espaço geográfico de interação do ar, do mar e da terra, incluindo seus recursos renováveis ou não, abrangendo uma faixa marítima e outra terrestre, que serão definidas pelo Plano". O PNGC I, aprovado pela Resolução CIRM ${ }^{21} \mathrm{n}^{\circ}$ 001/1990, estabeleceu critérios físico-ambientais - tais como a não fragmentação da unidade natural dos ecossistemas costeiros, a linha de cristas da configuração topográfica do litoral, o espaço submerso até onde ocorrem movimentos (ondas, correntes e marés) que possam ocasionar processos naturais capazes de afetar a natureza da costa, bem como as áreas marcadas por intensa atividade socioeconômica capazes de delimitar a ZC. Como cada Estado litorâneo brasileiro apresenta uma configuração, o PNGC I deixou a definição dos limites terrestre e marítimo da ZC para os Planos Estaduais de Gerenciamento Costeiro. Apenas na ausência de estudos técnicos suficientes para a aplicação daqueles critérios é que o PNGC I definiu uma regra clara: para a faixa marítima - que é a que importa para fins deste artigo -, 6 milhas marítimas $(11,1 \mathrm{~km})$ sobre uma perpendicular, contadas a partir da Linha de Costa. Portanto, as usinas eólicas offshore implantadas até 6 milhas marítimas de distância da costa deviam vir contempladas no PNGC I. O Art. $5^{\circ}$ da Lei ${ }^{\circ}$ 7.661/88 menciona expressamente os "sistemas de produção, transmissão e distribuição de energia" como um aspecto a ser considerado no PNGC.

O PNGC I deu lugar ao PNGC II, aprovado pela Resolução CIRM $\mathrm{n}^{\circ}$ 005/1997, onde, de forma mais direta e simples, estabelece que a Faixa Maritima - "faixa que se estende mar afora distando 12 milhas maritimas

21 Conselho Interministerial para os Recursos do Mar. 
das Linhas de Base estabelecidas de acordo com a Convenção das Nações Unidas sobre o Direito do Mar, compreendendo a totalidade do Mar Territorial" - faz parte da ZC. Portanto, eólicas offshore instaladas até 12 milhas maritimas distantes da costa devem constar do PNGC.

O uso dos ventos marítimos para geração de eletricidade também é mencionado no Decreto $\mathrm{n}^{\circ}$ 8.907, de 22 de novembro de 2016, que aprova o IX Plano Setorial para os Recursos do Mar - PSRM. Na definição do PNRM “os recursos do mar são todos os recursos vivos, não vivos, incluindo os energéticos existentes nas áreas marinhas sob jurisdição nacional e nas áreas internacionais de interesse, bem como na Zona Costeira, cujo aproveitamento e cuja conservação são relevantes sob os pontos de vista econômico, social e ambiental, promovendo o uso, a conservação e a exploração e a explotação sustentável desses recursos".

O IX PSRM destaca em sua introdução o potencial dos recursos naturais marinhos para a produção de energia a partir de fontes renováveis, como energia eólica, de ondas e de marés. Ressalta a necessidade de compatibilizar a gestão de áreas protegidas com a conservação da biodiversidade e o uso sustentável dos recursos naturais. O IX PSRM contempla quatro áreas principais: (i) recursos vivos, (ii) recursos não vivos, (iii) monitoramento e observação dos oceanos e estudos do clima e (iv) recursos humanos em Ciências do Mar. Recursos energéticos advindos do aproveitamento dos ciclos de marés, ondas, correntes, ventos, gradientes térmicos, dentre outros, são expressamente considerados recursos marinhos não vivos, pela definição do PSRM. As atividades de geração de energia no ambiente marinho, bem como as de mineração, requerem estudos de viabilidade técnica, econômica e ambiental, requisitos necessários ao estabelecimento de políticas públicas voltadas para tais atividades.

Embora tenha feito o destaque ao potencial dos recursos energéticos, o PSRM, ao tratar dos recursos não vivos, atem-se apenas aos recursos minerais e, nas nove ações a empreender elencadas pelo IX PSRM, não há ação concreta relacionada ao aproveitamento dos ventos marítimos, nem mesmo relacionada às medições anemométricas. É salutar, de todo modo, a menção ao uso dos recursos marítimos para geração de eletricidade. 


\section{O DIREITO AMBIENTAL NA CNUDM APLICÁVEL ÀS USINAS EÓLICAS OFFSHORE}

De forma pioneira, a produção de energia a partir dos ventos é expressamente mencionada no Art. 56 da Convenção das Nações Unidas para o Direito do Mar - CNUDM ${ }^{22}$. No âmbito da proteção ambiental, o Art. 56, item 1, alínea "b", da CNUDM, afirma que o Estado costeiro tem jurisdição, na ZEE, no que se refere a proteção e preservação do meio marinho. O Art. 21, item 1, alínea “f” dispõe igualmente para o mar territorial.

Toda a Parte XII da Convenção é dedicada à proteção e preservação do meio marinho. Todos os Estados têm a obrigação de proteger e preservar o meio marinho (Art. 192), tomando todas as medidas necessárias para prevenir, reduzir e controlar a poluição do meio marinho (Art. 194, item 1), o que inclui medidas destinadas a reduzir, tanto quanto possível, a poluição proveniente de instalações e dispositivos que funcionem no meio marinho - o que inclui aerogeradores offshore -, em particular medidas para prevenir acidentes e enfrentar situações de emergência, garantir a segurança das operações no mar e regulamentar o projeto, construção, equipamento, funcionamento e tripulação de tais instalações ou dispositivos (Art. 194, item 3, alínea "d"). Dentre as medidas, merece destaque a avaliação e publicação de relatórios, por parte do Estado costeiro, dos potenciais efeitos poluidores e nocivos de atividades projetadas sob sua jurisdição, as quais possam prejudicar e modificar significativamente o meio marinho (Art. 206) ${ }^{23}$. Ainda, pelo Art. 208 devem os Estados costeiros adotar leis e regulamentos para prevenir, reduzir e controlar a poluição do meio marinho, proveniente direta ou indiretamente de atividades relativas aos fundos marinhos sob sua jurisdição e proveniente de ilhas artificiais, instalações e estruturas dentre elas, aerogeradores offshore - sob sua jurisdição, nos termos dos Arts. 60 e 80 .

Restaria saber se os impactos ambientais potencialmente

\footnotetext{
22 Entrada em vigor no Direito brasileiro pelo Decreto ${ }^{\circ} 1.530$, de 22 de junho de 1995.

23 No âmbito internacional encontra-se a Convenção Relativa à Avaliação dos Impactos Ambientais num Contexto Transfronteiriço, de 1991, que estabeleceu critérios de avaliação das Partes sobre o impacto ambiental de certas atividades, estabelecendo a imposição de notificação e de consultas sobre projetos que possam ter um impacto ambiental nocivo transfronteiras. O Anexo I da Convenção, atualizado em 2004, traz uma lista de atividades passíveis de terem um impacto ambiental transfronteiriço nocivo, incluindo instalações para produção de energia eólica. O Brasil não é Estado-Parte desta Convenção.
} 
causados pela instalação e operação de aerogeradores offshore podem ser considerados "poluição do meio marinho" para fins de aplicação da CNUDM. O Art. $1^{\circ}$ da Convenção define poluição do meio marinho como "a introdução pelo homem, direta ou indiretamente, de substâncias ou de energia no meio marinho, incluindo os estuários, sempre que a mesma provoque ou possa vir provocar efeitos nocivos, tais como danos aos recursos vivos e à vida marinha, riscos à saúde do homem, entrave às atividades marítimas, incluindo a pesca e as outras utilizações legítimas do mar, alteração da qualidade da água do mar, no que se refere à sua utilização, e deterioração dos locais de recreio". Note-se que o conceito é abrangente, incluindo não apenas a introdução de substâncias nocivas no meio marinho, mas também qualquer forma de energia, o que inclui a energia gerada, por exemplo, pelo campo eletromagnético advindo do fluxo de eletricidade presente no cabo de transmissão (energia térmica) ou, ainda, pela vibração e ruído causados pela instalação e operação dos aerogeradores offshore (energia cinética).

Nesse sentido, a exploração de potencial eólico offshore é atividade potencialmente causadora de poluição do meio marinho, devendo seu exercício respeitar o disposto na Parte XII da Convenção.

\section{REGULAMENTAÇÃO AMBIENTAL ESTRANGEIRA PERTINENTE ÀS USINAS EÓLICAS OFFSHORE}

Beneficiando-se do ainda inexistente florescimento de uma indústria eólica offshore nacional, pode-se extrair importantes lições ("Do's and Dont's") das experiências internacionais no âmbito da regulação jurídica de empreendimentos eólicos offshore. Os temas cujo tratamento legal é indispensável relacionam-se a regime de concessão, agentes governamentais, acesso e conexão ao sistema de transmissão - e quem paga por isso - e condicionantes ambientais. Atendo-se ao escopo do artigo, serão trazidos os instrumentos jurídicos encontrados no Direito estrangeiro para gerir e proteger o meio ambiente quando da instalação de aerogeradores no $\operatorname{mar}^{24}$.

24 Esta seção não trata de fazer uma análise completa da regulação das usinas eólicas offshore internacionalmente, mas simplesmente de pinçar a matéria ambiental pertinente. 


\subsection{Dinamarca}

O permissivo legal para a exploração econômica do potencial eólico offshore dinamarquês consta do Promotion of Renewable Energy Act (Act $\mathrm{n}^{\circ} 1.392$ ), de 27 de dezembro de $2008^{25}$, onde seu capítulo 3 regulamenta especificamente as usinas eólicas offshore, merecendo destaque o artigo 22, parágrafo 1, de onde consta, expressamente, o direito exclusivo do Estado Dinamarquês para explorar energia a partir da água e do vento dentro do Mar Territorial e da ZEE dinamarquesa.

Quanto ao meio ambiente, parte-se da premissa que usinas eólicas offshore causam impacto ambiental e que, portanto, a elaboração de EIA, nos termos do artigo 26, parágrafo 1 ss. do $A c t \mathrm{n}^{\circ} 1.392$, de 2008, e da Executive Order $\mathrm{n}^{\circ}$ 68, de 26 de janeiro de 2012, é indispensável. Até o momento, todos os projetos eólicos offshore na costa da Dinamarca precisaram de estudos de impacto ambiental, os quais seguem diretivas desenvolvidas pela própria Agência reguladora dinamarquesa (Energistyrelsen ${ }^{26}$.

$\mathrm{O}$ artigo 27, por sua vez, determina que projetos eólicos offshore que ameacem a integridade de áreas de conservação internacionais devem apenas ser aprovados após elaboração de estudo quanto às implicações de tal projeto para os objetivos de conservação da área afetada. Essa aprovação apenas será concedida após a oitiva das partes e órgãos envolvidos e ficar atestado que tais projetos não danificam a integridade da área de conservação internacional ou existam razões de interesse público que tornem a construção do projeto imperativa, em vista da falta de solução alternativa. Neste último caso, medidas compensatórias serão estabelecidas.

Ainda, demonstrado tratar-se a área de conservação internacional de espaço que abriga tipos de habitats naturais prioritários ou espécies prioritárias, a aprovação para o projeto apenas será concedida quando restar demonstrada a necessidade do projeto para a saúde humana, segurança pública ou visando obter consequências benéficas de importância primária para o meio ambiente. Para áreas de conservação ambiental internacionais, portanto, estabeleceu a lei dinamarquesa requisitos mais rígidos para a implementação de projetos eólicos offshore.

25 Disponível em: https://ens.dk/sites/ens.dk/files/Vindenergi/promotion_of_renewable_energy_ act___extract.pdf. Acesso em 10.11.2016.

26 Disponível em: https://ens.dk/en/our-responsibilities/wind-power/offshore-procedures-permits. Acesso em: 10.11.2016. 
Por fim, para as áreas de conservação internacionais pode ser estabelecida a proibição de construção de aerogeradores offshore, a critério do Ministro do Clima e Energia, de modo a evitar a deterioração de habitats naturais e o distúrbio de espécies que habitam a área designada (artigo 28).

Ponto importante da avaliação de impacto ambiental é a poluição sonora causada durante a construção e fundação das torres eólicas (piledriving noise). Em uma típica licença para construção de usina eólica offshore ${ }^{27}$, consta a obrigação de que parte dos estudos ambientais contenha um prognóstico das características da fonte de ruído bem como das características da propagação sonora. Para o caso dinamarquês, o nível de exposição sonora (sound exposure level - SEL) ${ }^{28}$ máximo a que um mamífero aquático pode se submeter quando das obras de fundação não pode exceder $190 \mathrm{~dB}$.

A atividade de monitoramento dos impulsos sonoros para as atividades relacionadas à construção dos aerogeradores offshore precisa ser comunicada à Agência reguladora dinamarquesa, sendo informado a data da atividade sonora, local, nível sonoro e a atividade causadora do impulso sonoro. Além disso, o concessionário deve submeter estudo à Agência dinamarquesa de onde conste: (i) previsão do nível de ruído sonoro e propagação do ruído de ao menos quatro pilares; (ii) cálculo do SEL acumulado, levando em consideração a utilização de sonares e outros equipamentos para repelir a presença de mamíferos marinhos em ao menos 1,3km; (iii) declaração das medidas de abatimento sonoro planejadas; e (iv) programa para controle de medição quando da instalação de pilare ${ }^{29}$. Tratase, portanto, de regramento já com algum grau avançado de detalhamento.

Vale mencionar, ainda, o Relatório Future Offshore Wind Power Sites, elaborado pela Agência e que contém as áreas que serão licitadas. Ponto de destaque do órgão regulador dinamarquês (Energistyrelsen) é a constante atualização do plano de ação para usinas eólicas offshore, o qual guia a política energética para esse nicho no setor no que tange a integração à rede, tráfego de embarcações, considerações ambientais e identificação de áreas protegidas ${ }^{30}$.

27 Cf. exemplo disponível em: https://ens.dk/sites/ens.dk/files/Vindenergi/bilag_6_model_for_etableringstilladelse_vesterhav_nord_eng_final.pdf. Acesso em: 29.01.2017.

28 As fórmulas de cálculo para se obter o SEL constam de uma diretiva do órgão regulador dinamarquês (Danish Energy Agency's guidelines on underwater noise when pile driving), disponível em: https:/ens.dk/sites/ens.dk/files/Vindenergi/guideline_underwater_noise_april_2016_0.pdf. Acesso em: 29.01.2017.

29 Disponível em: https://ens.dk/sites/ens.dk/files/Vindenergi/bilag_6_model_for_etableringstilladelse_vesterhav_nord_eng_final.pdf. Acesso em: 29.01.2017.

30 WORLD BANK; NATIONAL ENERGY ADMINISTRATION OF CHINA. China-Meeting the 


\subsection{Alemanha}

A Alemanha passou a explorar o potencial eólico offshore em razão do esgotamento das áreas propícias à instalação de usinas eólicas onshore. Havendo estipulado a ousada meta de $80 \%$ de participação das energias renováveis no consumo bruto de eletricidade até 2050 (Art. 1, parágrafo 2, da Gesetz für den Ausbau erneuerbarer Energien, também conhecida por Erneuerbare-Energien-Gesetz - EEG 2017 $7^{31}$ ), aliada à decisão do governo de fechar todas as suas usinas nucleares até 2022, a exploração do potencial eólico offshore tornou-se componente indispensável da matriz elétrica alemã.

Desde $1^{\circ}$ de janeiro de 2017 entrou em vigor a Lei da energia eólica offshore (Windenergie-auf-See-Gesetz - WindSeeG) alemã, criada pela Lei para introdução de leilões para eletricidade a partir de energias renováveis e para demais alterações do Direito das Energias Renováveis ${ }^{32}$, aprovada em 8 de julho de 2016. Objetivo da WindSeeG consiste em aumentar a capacidade instalada de usinas eólicas offshore para 15GW até 2030 (Art. $1^{\circ}$, parágrafo segundo, WindSeeG). De acordo com o plano para projetos de parques eólicos offshore, até 2020 devem 7,7GW de capacidade instalada estar conectados à rede.

Ponto importante da regulação alemã sob a perspectiva ambiental diz respeito ao planejamento espacial marítimo. Um plano de desenvolvimento de áreas é estabelecido a partir de uma íntima interação entre a Agência Federal para Navegação Marítima e Hidrografia (Bundesamt für Seeschifffahrt und Hydrographie), a agência reguladora alemã (Bundesnetzagentur) e a Agência Federal para a Preservação do Meio Ambiente (Bundesamt für Naturschutz), de forma a delimitar onde os parques eólicos podem ser erguidos, como e quando essas áreas serão exploradas (Art. 17-A e seguintes da Energiewirtschaftsgesetz - EnWG, para determinações e compromissos traçados no plano até 2026, bem como Art. $5^{\circ}$ e Art. $6^{\circ}$, parágrafo sétimo, da WindSeeG, para determinações e compromissos a partir de 2026) ${ }^{33}$. Trata-se do principal instrumento de

challenges of offshore and large-scale wind power: regulatory review of offshore wind in five European countries. Washington: World Bank, 2010, p. 9.

31 Lei para o desenvolvimento das energias renováveis, também conhecida por Lei das energias renováveis, sendo de 2017 a última atualização da Lei.

32 Gesetz zur Einführung von Ausschreibungen für Strom aus erneuerbaren Energien und zu weiteren Änderungen des Rechts der erneuerbaren Energien.

33 Deste plano (Flächenentwicklungsplan), estabelecido na WindSeeG e que, conforme Art. $7^{\circ}$ da 
planejamento da exploração eólica offshore na Alemanha.

Estudos de prospecção para a delimitação da área a ser licitada devem considerar os seguintes elementos: análise ambiental estratégica; análise espacial dos aspectos ambientais técnicos e de outros bens a serem protegidos; pré-análise do subsolo marinho; análise quanto a possíveis colisões de embarcações; e avaliação e medição dos ventos ${ }^{34}$. Apenas podem ser licitados parques eólicos localizados nas áreas aprovadas no plano.

O vencedor do certame, para obter a aprovação para construir e concessão para explorar o potencial eólico offshore ofertado em leilão, deve apresentar previamente perante a Agência Federal para Navegação Marítima e Hidrografia um plano, o qual precisa ser aprovado (Artigo 45 da WindSeeG). O plano apresentado pelo vencedor do certame apenas será aprovado quando (i) o ambiente marinho não estiver ameaçado, em especial no que diz respeito à poluição do ambiente marinho de que trata a CNUDM e à preservação das rotas das aves; (ii) a segurança e fluidez do transporte marítimo estiver garantida; (iii) a defesa nacional não estiver ameaçada; (iv) este estiver em consonância com atividades minerárias prioritárias; (v) este estiver em consonância com a existência de cabos, demais conexões, bem como com a localização de plataformas conversoras e transformadores já existentes e planejados; (vi) não houver pendências ou condicionantes perante a Agência Federal para Navegação Marítima e Hidrografia (Artigo 47, parágrafo quarto, da WindSeeG).

Com relação ao ruído sonoro na coluna d'água, desde 2008 consta das autorizações dadas pela Agência Federal para Navegação Marítima e Hidrografia a obrigação de limitar o nível de exposição sonora em 160dB em até 750 metros de distância do local das obras ${ }^{35}$. Além disso, algumas tecnologias estão sendo desenvolvidas para minimizar distúrbios sonoros, dentre elas: cortina de bolhas, Hydro Sound Damper e ensecadeiras ao

WindSeeG, substitui o plano (Bundesfachplan Offshore) criado pelo Art. 17-A e seguintes da EnWG), devem constar as áreas da ZEE alemã passíveis de instalação de aerogeradores offshore, a ordem em que as áreas devem ser licitadas, o ano de entrada em operação das usinas, a capacidade instalada de cada aerogerador, localização das instalações de transmissão (transformadores, subestações etc.), traçados das linhas de transmissão, possíveis conexões e traçados de linhas que ultrapassem a ZEE alemã e que possam se integrar a outros países, e standards técnicos e de planejamento a serem observados (Art. $5^{\circ}$, parágrafo primeiro da $W i n d S e e G$ ).

34 BUNDESMINISTERIUM FÜR WIRTSCHAFT UND ENERGIE. Ausschreibungen für die Förderung von Erneuerbare-Energien-Anlagen. Berlim: Bundesministerium für Wirtschaft und Energie, 2015, p. 13.

35 BUNDESMINISTERIUM FÜR WIRTSCHAFT UND ENERGIE. Offshore-Windenergie - Ein Überblick über die Aktivitäten in Deutschland. Berlim: Bundesministerium für Wirtschaft und Energie, 2015, p. 28. 
redor da área onde ocorre o pile-driving ${ }^{36}$. Especialmente para o boto (Phocoenidae) no Mar do Norte, foi desenvolvido pelo Ministério do Meio Ambiente (Bundesumweltministerium) em dezembro de 2013 um conceito para sua proteção contra os ruídos sonoros, que contém medidas adicionais para a diminuição dos impactos ambientais causados pelo barulho oriundo das obras de fundição dos aerogeradores offshore ${ }^{37}$.

Estudos de impacto ambiental são obrigatórios para empreendimentos eólicos acima de 20 turbinas, sendo que para parques eólicos com 6 a 20 turbinas o EIA é obrigatório quando análise preliminar identificar possíveis desvantagens ambientais causadas pelo empreendimento. Para empreendimentos menores, de 3 a 6 turbinas, vale o mesmo se análise preliminar local identificar riscos ao meio ambiente local (Art. $3^{\circ}-\mathrm{C}$ da Umweltverträglichkeitsprüfungsgesetz ${ }^{38}$ ).

\subsection{Reino Unido}

Do ponto de vista regulatório, o Reino Unido delimitou sua ZEE por meio da Exclusive Economic Zone Order 2013, cujo Artigo 2 expressamente afirma que as áreas ali definidas são áreas dentro das quais os direitos constantes da Parte V da CNUDM podem ser exercidos pelo Reino Unido. Ademais, a Seção 84 do Energy Act 2004 refere-se expressamente aos direitos constantes da Parte V da CNUDM, exercidos pelo Reino Unido para além de seu Mar Territorial e relacionados, entre outros, à geração de eletricidade a partir dos ventos.

Será designada, conforme Seção 84(4), uma área marinha onde tais direitos poderão ser exercidos (Renewable Energy Zone). De forma detalhada, o Energy Act 2004 regula a aplicação da lei penal e da lei cível às instalações eólicas offshore, bem como o procedimento licitatório, forma de outorga das licenças para exploração, autorização para geração de eletricidade, estabelecimento de áreas de segurança ao redor das instalações e atividades proibidas dentro destas áreas, e direitos e deveres com relação à navegação e aviação civil dentro de uma Renewable Energy Zone (Seções 85 a 101).

\footnotetext{
36 Disponível em: https://www.bfn.de/22515.html. Acesso em: 30.01.2017.

37 BUNDESMINISTERIUM FÜR UMWELT, NATURSCHUTZ UND REAKTORSICHERHEIT. Konzept für den Schutz der Schweinswale vor Schallbelastungen bei der Errichtung von Offshore-Windparks in der deutschen Nordsee (Schallschutzkonzept). Berlim: Bundesministerium für Umwelt, Naturschutz und Reaktorsicherheit, 2013.
}

38 Lei do Estudo de Impacto Ambiental. 
No Reino Unido, a Crown Estate é o órgão responsável por gerir grande parte das águas do Reino Unido, os direitos à exploração dos recursos naturais (exceto combustíveis fósseis) na Plataforma Continental, bem como gerir os direitos de geração de eletricidade a partir do vento, ondas e marés, e de transporte e armazenamento de gás natural e dióxido de carbono na Plataforma Continental. O Department for Energy and Climate Change é responsável pela condução de Strategic Environmental Assessment ${ }^{39}$, com o intuito de verificar quais áreas são passíveis de receberem aerogeradores offshore, em razão das implicações ambientais advindas da potencial exploração do potencial eólico ${ }^{40}$. Esses estudos são passados a Crown Estate. Na elaboração do Strategic Environmental Assessment, contudo, dá-se ao aproveitamento eólico offshore tratamento regulatório parecido ao que é dado à exploração offshore de petróleo e gás, como se ambos tivessem o mesmo potencial de impacto ao meio ambiente, situação essa criticada na literatura ${ }^{41}$.

O desenvolvedor do projeto é obrigado a realizar uma série de estudos técnicos e ambientais, de forma a obter autorizações (statutory consents) para construção e desenvolvimento do projeto. Apenas de posse destas autorizações lhe é garantido o Agreement for Lease, o qual garante a uma empresa a opção de desenvolver um projeto em uma determinada área do subsolo marinho. Os estudos devem conter, em linhas gerais, os detalhes do projeto, o EIA, documentação que comprove as consultas às partes interessadas e identificação de possíveis entraves à viabilização do projeto e quais soluções podem ser adotadas ${ }^{42}$. De acordo com a Town and Country Planning Regulation 2011, o EIA não é obrigatório para usinas eólicas offshore. Contudo, será necessário caso o projeto "possivelmente tenha impactos significantes no meio ambiente em razão de fatores tais como sua natureza, tamanho e localização" ${ }^{\prime 4}$.

Vale ainda ser destacada a criação do Collaborative Offshore Wind

39 Sendo o mais atual o Offshore Energy Strategic Environmental Assessment (OESEA3), de 2016.

40 DEPARTMENT OF ENERGY \& CLIMATE CHANGE. UK Offshore Energy Strategic Environmental Assessment. 2016, p. 1. Disponível em: https:/www.gov.uk/government/uploads /system/uploads/attachment_data/file/504874/OESEA3_Non-technical_summary.pdf. Acesso em: 30.01.2017. Ainda, o Marine and Coastal Access Act $20 \overline{0} 9$ permite a criação de Marine Conservation Zones - Inglaterra, Gales e Irlanda do Norte - e Marine Protected Areas - Escócia.

41 CAINE, Catherine. The dogger bank offshore wind farm proposal: a study of the legal mechanisms employed in the construction of an offshore wind farm. In: North East Law Review, vol. 2, 2014, p. 123.

42 Disponível em: https://www.thecrownestate.co.uk/media/5411/ei-the-crown-estate-role-in-offshore-renewable-energy.pdf. Acesso em: 18.11.2016.

43 CAINE, Catherine. The dogger bank offshore wind farm proposal: a study of the legal mechanisms employed in the construction of an offshore wind farm. In: North East Law Review, vol. 2, 2014, p. 101. 
Research into the Environment - COWRIE, órgão independente criado pela Crown Estate, com o objetivo de conduzir pesquisas sobre os impactos ao meio ambiente causados pela execução de projetos eólicos offshore ${ }^{44}$.

\subsection{Estados Unidos}

Nos Estados Unidos o desenvolvimento da indústria eólica offshore é relativamente recente em comparação à Europa. As motivações que impulsionam o desenvolvimento de usinas eólicas offshore baseiam-se não no esgotamento do potencial eólico onshore, mas sim nos crescentes preços do carvão, gás natural e petróleo, bem como na necessidade de depender cada vez menos de fontes externas de suprimento de energia (busca pela independência energética, tida como questão de segurança nacional $)^{45}$.

O permissivo legal encontra-se na Seção 388 do Energy Policy Act 2005, que alterou a Seção 8 do Outer Continental Shelf Lands Act, permitindo o uso da Plataforma Continental para geração de energia a partir de fontes renováveis. Proteção do meio ambiente, prevenção de resíduos e conservação dos recursos naturais são três requisitos expressamente mencionados, dentre outros, no dispositivo legal.

O órgão responsável pela emissão de concessões para desenvolvimento de projetos eólicos na Plataforma Continental norteamericana é o Bureau of Ocean Energy Management (BOEM), conforme estabelecido na Seção 388 do Energy Policy Act 2005. De forma a dar suporte no estabelecimento do seu programa para a emissão de concessões de projetos de energias renováveis, BOEM preparou o Programmatic Environmental Impact Statement $(P E I S)^{46}$, espécie de relatório extenso que examina pormenorizadamente os potenciais efeitos ambientais na Plataforma Continental e identifica políticas e best practices que devem ser adotadas pelo desenvolvedor do projeto eólico.

\footnotetext{
44 Para uma listagem dos estudos já conduzido pela COWRIE, cf. https://www.thecrownestate.co.uk/ media/5491/cowrie reports held by the crown estate.pdf. Acesso em: 30.01.2017.

45 SNYDER, Brian; Mark J. Kaiser. A comparison of offshore wind power development in Europe and the US: Patterns and drivers of development. In: Applied Energy, vol. 86, 2009, p. 1845.

46 Disponível em: https://www.boem.gov/Renewable-Energy-Program/Regulatory-Information/Guide-To-EIS.aspx. Acesso em: 30.01.2017.
} 


\section{CONCLUSÃO}

De todo o exposto, percebe-se que já há, ao menos no Direito estrangeiro, alto grau de regulamentação das usinas eólicas offshore pelo Direito Ambiental Marinho. Diversos instrumentos foram criados na legislação estrangeira para fazer frente à necessidade de conciliação entre o desenvolvimento das fontes renováveis de energia - aqui, em especial a fonte eólica - e a proteção ao meio ambiente marinho: regulação detalhada e limites claros quanto ao nível de exposição sonora dos mamíferos aquáticos durante as obras de fundação e operação da usina; estabelecimento de zonas de energias renováveis, a exemplo da licitação por blocos ocorrida no setor de petróleo e gás; criação de órgão independente para pesquisas relacionadas aos impactos ambientais causados pela exploração da energia eólica offshore. Ainda, vale citar também a possibilidade de estabelecimento de zonas de exclusão, dentro das quais a exploração econômica dos ventos marítimos é proibida ${ }^{47}$. Por fim, a obrigatoriedade ou não de Estudo de Impacto Ambiental é ponto presente em todas as regulamentações analisadas.

Com relação ao ordenamento brasileiro, ainda não há um regramento específico para a exploração dos ventos eólicos offshore, embora algumas disposições de Direito Ambiental sejam aplicáveis ao caso. Em razão da novidade tecnológica e dos inovadores arranjos de engenharia para construção de projeto eólicos offshore, em águas cada vez mais profundas e distantes da costa, pouco ainda se sabe sobre os impactos ambientais na vida marinha, motivo pelo qual faz-se necessária certa cautela no licenciamento ambiental destes empreendimentos. É importante que a proteção às espécies marinhas afetadas pela instalação de usinas eólicas seja garantida. Nesse sentido, aos projetos de usinas eólicas offshore não devem ser facultados a adoção da via do procedimento simplificado para licenciamento ambiental, tal qual vigora, conforme $\S 2^{\circ}$ do Art. $3^{\circ}$

47 O Estudio Estratégico Ambiental del litoral español para la instalación de parques eólicos marinos" espanhol divide o zoneamento do espaço marinho em três: "Zonas de exclusión", que são zonas consideradas inaptas para a instalação de parques eólicos offshore, por haverem sido identificados potenciais efeitos ambientais incompatíveis com a atividade; "Zonas aptas con condicionantes ambientales", representadas por zonas onde se deduz a possibilidade de ocorrência de determinados efeitos ambientais negativos, fazendo-se necessário, portanto, um aprofundamento da avaliação de impacto ambiental causado pelos correspondentes projetos; e "Zonas aptas", que são zonas em que não se detectou impacto ambiental significativo que prejudique o desempenho da atividade econômica, disponível em: http:/www.aeeolica.org/uploads/documents/562-estudio-estrategico-ambiental-del-litoral-espanol-para-la-instalacion-de-parques-eolicos-marinos_mityc.pdf. Acesso em: 30.01.2017. 
da Resolução CONAMA 462/14, para empreendimentos eólicos onshore de baixo impacto ambiental, sendo indispensável, aos projetos offshore, a elaboração de EIA/RIMA.

Um EIA deve abordar, em maior ou menor profundidade, a depender do caso, aspectos relacionados a: uso e conservação do solo terrestre e do subsolo marinho, dragagem e eliminação de resíduos, cabos submarinos, interferência com plataformas para extração de petróleo e gás existentes, pesca, aves e rotas migratórias, navegação, portos e aviação, arqueologia, processos costeiros, atividades recreativas, culturais, de lazer e militares, extração mineral, dentre outros. Condicionantes para implementação de projetos e formas de compensação devem constar de qualquer análise do órgão ambiental.

Ainda, e visando a preservação do ambiente costeiro e a mitigação da poluição visual, é recomendável a criação de zonas de exclusão, em especial nas áreas confluentes com Unidades de Conservação ${ }^{48}$. Deve ser observado o que dispõe o Plano Nacional de Gerenciamento Costeiro PNGC e o Plano Setorial para os Recursos do Mar - PSRM. Em outra frente, é importante que haja regramento estabelecendo a forma de trabalho conjunto dos órgãos de regulação e fiscalização ambiental e de preservação do meio marinho - IBAMA e ICMBio - com o órgão regulador do setor elétrico - ANEEL.

Faz-se imperioso que a exploração dos ventos eólicos offshore seja regulamentada, de forma que a proteção ao clima - buscada pelo uso de fontes renováveis de energia em substituição aos combustíveis fósseis não conflita com a proteção ao meio ambiente.

\section{REFERÊNCIAS}

AMARANTE, Odilon Camargo et al. Atlas do potencial eólico brasileiro. Brasília: Ministério de Minas e Energia, 2001.

BAILEY, Helen; BROOKES, Kate L.; THOMPSON, Paul M. Assessing environmental impacts of offshore wind farms: lessons learned and recommendations for the future. Aquatic Biosystems, v. 10, n. 8, 2014. Disponível em: $<$ https://aquaticbiosystems.biomedcentral.com/track/ pdf/10.1186/2046-9063-10-8>. Acesso em: 13 maio 2019.

48 Disponível em: http://www.icmbio.gov.br/portal/unidadesdeconservacao/biomas-brasileiros/ marinho/unidades-de-conservacao-marinho. Acesso em: 24 nov. 2016. A respeito, cf. LEUZINGER, Márcia Dieguez; SILVA, Solange Teles da. Unidades de Conservação marinhas. In: OLIVEIRA, Carina da Costa (org.). Meio ambiente marinho e Direito. Curitiba: Juruá, 2015. p. 253. 
BUNDESMINISTERIUM FÜR UMWELT, NATURSCHUTZ UND REAKTORSICHERHEIT. Konzept für den Schutz der Schweinswale vor Schallbelastungen bei der Errichtung von Offshore-Windparks in der deutschen Nordsee (Schallschutzkonzept). Berlin: Bundesministerium für Umwelt, Naturschutz und Reaktorsicherheit, 2013.

BUNDESMINISTERIUM FÜR WIRTSCHAFT UND ENERGIE. Ausschreibungen für die Förderung von Erneuerbare-Energien-Anlagen. Berlim: Bundesministerium für Wirtschaft und Energie, 2015.

. Offshore-Windenergie - Ein Überblick über die Aktivitäten in Deutschland. Berlin: Bundesministerium für Wirtschaft und Energie, 2015.

CAINE, Catherine. The dogger bank offshore wind farm proposal: a study of the legal mechanisms employed in the construction of an offshore wind farm. North East Law Review, v. 2, p. 89-127, 2014.

DEPARTMENT OF ENERGY \& CLIMATE CHANGE. UK Offshore Energy Strategic Environmental Assessment, 2016.

GILL, A. B.; BARLETT, M. (2010). Scottish Natural Heritage, Commissioned Report, n. 401: literature review on the potential effects of electromagnetic fields and subsea noise from marine renewable energy developments on Atlantic salmon, sea trout and European eel. Inverness: Scottish Natural Heritage, 2010.

GUIMARÃES, Lucas Noura de Moraes Rêgo. Geração de eletricidade a partir de usinas eólicas offshore: premissas a serem consideradas. In: BORGES, Thiago Carvalho; ZANELLA, Thiago V.; TOLEDO, André de Paiva; SUBTIL, Leornardo de Camargo; BORGES, Orlindo Francisco (Orgs.). Direito do mar: reflexões, tendências e perspectivas. (v. 1.). Belo Horizonte: D’Plácido, 2017.

LEUZINGER, Márcia Dieguez; SILVA, Solange Teles da. Unidades de conservação marinhas. In: OLIVEIRA, Carina da Costa (Org.). Meio ambiente marinho e Direito. Curitiba: Juruá, 2015.

PETERSEN, Ib Krag et al. Final results of bird studies at the offshore wind farms at Nysted and Horns Rev, Denmark. Roskilde: National Environmental Research Institute, 2006. 
SNYDER, Brian; KAISER, Mark J. A comparison of offshore wind power development in Europe and the US: Patterns and drivers of development. Applied Energy, v. 86, n. 10, p. 1845-1856, 2009.

THOMPSON, Paul M. et al. Framework for assessing impacts of piledriving noise from offshore wind farm construction on a harbour seal population. Environmental Impact Assessment Review, v. 43, p. 73-85, 2013.

WORLD BANK; NATIONAL ENERGY ADMINISTRATION OF CHINA. China-Meeting the challenges of offshore and large-scale wind power: regulatory review of offshore wind in five European countries. Washington: World Bank, 2010.

ZAMPIERI, Natália; CABRAL, Mariana. Os vieses da biodiversidade apresentados pelo caso do parque é́lico de Bald Hills. Revista de Direito Internacional, v. 13, n. 2, p. 261-274, 2016.

ZEUSCHNER, Ruven Fleming. Pipelines and cables: the offshore transportation of oil, gas and renewable energy. International Energy Law Review, v. 29, n. 8, p. 311-326, 2011.

Artigo recebido em: 18/07/2018.

Artigo aceito em: 06/02/2019.

\section{Como citar este artigo (ABNT):}

GUIMARÃES, L. N. M. R. Usinas eólicas offshore no direito ambiental marinho. Veredas do Direito, Belo Horizonte, v. 16, n. 34, p. 153-176, jan./abr. 2019. Disponível em: <http://www.domhelder. edu.br/revista/index.php/veredas/article/view/1214>. Acesso em: dia mês. ano. 